\title{
Thymoquinone and Costunolide Induce Extensive Apoptosis of Senescent Colon and Senescent Breast Cancer Cells
}

\author{
Ali H El-Far ( $\square$ ali.elfar@damanhour.edu.eg ) \\ Damanhour University Faculty of Veterinary Medicine https://orcid.org/0000-0001-9721-4360 \\ Ahmed E. Noreldin \\ Damanhour University Faculty of Veterinary Medicine \\ Soad K. Al Jaouni \\ King Abdulaziz Medical City - Jeddah \\ Shaker A. Mousa \\ Albany College of Pharmacy and Health Sciences
}

Research article

Keywords: Thymoquinone, Costunolide, Senescence, Apoptosis

Posted Date: August 7th, 2020

DOI: https://doi.org/10.21203/rs.3.rs-52516/v1

License: (c) (i) This work is licensed under a Creative Commons Attribution 4.0 International License. Read Full License 


\section{Abstract}

Several chemotherapeutic agents induce cancer cells' senescence as monitored by enlargement of cell, cell cycle arrest, elevated activities of senescence-associated $\beta$-galactosidase (SA- $\beta$-gal), and upregulation of p53 and p21. Doxorubicin (Dox) is an anticancer chemotherapeutic drug, classified as an anthracycline antibiotic, that induces senescence of numerous cancer cell types. The arrest of cancer cell growth is a bright face of senescence, while these senescent cancer cells relapse again if they are not eliminated. On this principle, we investigated the apoptotic effect of thymoquinone (TQ), the active ingredient of Nigella sativa seeds and costunolide (COS), the active ingredient of Costus speciosus, on senescent colon (Sen-HCT116) and senescent breast (Sen-MCF7) cancer cell lines in reference to their corresponding proliferative cells to rapidly eliminate the senescent cancer cells. The senescence markers of Sen-HCT116 and Sen-MCF7 were determined by significant decrease in bromodeoxyuridine (BrdU) incorporation and significant increases in SA- $\beta$-gal, p53, and p21 levels. After proliferative, Sen-HCT116, and Sen-MCF7 cells were subjected to either TQ $(50 \mu \mathrm{M})$ or $\operatorname{COS}(30 \mu \mathrm{M})$, the Bcl2-associated X protein (Bax), B-cell lymphoma 2 (Bcl2), and their ratio were established. Results revealed that TQ significantly increased the Bax/Bcl2 ratio in HCT116+Dox5+TQ, MCF7+TQ, and MCF7+Dox5+TQ compared with their corresponding controls. COS significantly increased the Bax/Bcl2 ratio in HCT116+Dox5+TQ and MCF7+Dox5+TQ compared with their corresponding controls. The data revealed more sensitivity of senescent cells to TQ or COS than their corresponding proliferative cells. Thus, we may be able to use TQ or COS to rapidly eliminate senescent cancer cells following Dox treatment; these results need to be confirmed with in vivo and clinical trials.

\section{Introduction}

The principal bioactive ingredient of Nigella sativa seeds is thymoquinone (TQ), which has a number of biological activities such as antioxidant, anticancer, and antitoxicant [1-6]. Gali-Muhtasib et al [7] stated that TQ prompted apoptosis of a human colon cancer (HCT116) cell line via a p53 dependence. Also, Dastjerdi et al [8] revealed that TQ induced apoptosis in a human breast cancer cell line (MCF7) through upregulation of p53 in a time-dependent manner. Moreover, TQ inhibited B-cell lymphoma 2 (Bcl2), which is anti-apoptotic in both in vitro and in vivo models [9].

Costunolide (COS) is a natural sesquiterpene lactone isolated from Costus speciosus roots that has anti-inflammatory, antioxidant, and anticancer effects [10]. COS targets a large number of important macromolecules, such as mitogen-activated protein kinases, protein kinase B, nuclear factor-k B, transcription signal transducer and activator and activator protein-1 [11]. Also, COS at doses of 40 and $80 \mu \mathrm{M}$ induced apoptosis of human lung squamous carcinoma cell line (SK-MES-1) through increases of p53 and Bax expressions and decreases of Bcl2 expression [12]. Similarly, Roy and Manikkam [13] observed significant upregulation of caspase 3 and caspase 9, which enhanced apoptosis of breast cancer cell lines (MCF7 and MDA-MB231).

Cellular senescence is an irreversible arrest of growth caused by various harmful stimuli [14]. The senescent cells have a larger and flattened cell form and elevation of senescence-associated $\beta$-galactosidase (SA- $\beta$-gal) activity $[15,16]$. Also, in senescence, p53 protein phosphorylation with p21 upregulation was recognized as leading to arrest of cell cycle [17]. Many chemotherapy medications at low doses change cancer cells' states and induce senescence features of treated cancer cells [18]. Cisplatin and doxorubicin (Dox) are the first chemotherapeutics reported to induce senescence in tumor cells [19,20]. Dox is a frequently used chemotherapy in the treatment of numerous cancers and it induces cell growth arrest with senescence markers [21, 22]. The senescent cells lose proliferation, migration, and invasion, and secrete a set of senescence-associated secretory phenotype (SASP), which influences normal cells and non-senescent cancer cells that induce tumor growth and recurring cancer cells [23]. Senescent cells have tumor-promoting effects on the surrounding microenvironment, as stated by Bavik et al [24] who found that coculture of senescent fibroblasts induced generation of preneoplasia of prostate epithelial cells. Also, Demaria et al [21] observed a relapse of tumor growth despite Dox-induced senescence and cell cycle arrest of tumors in a mice xenograft model. For this reason, in the current study we determined the ability of TQ and COS to induce apoptosis of Sen-HCT116 and Sen-MCF7 cell lines compared with their proliferative cells.

\section{Materials And Methods}

\subsection{Cell Lines}

Page 2/14 
Human colon HCT116 and breast MCF7 cancer cell lines were purchased from ATCC (Manassas, VA, USA). Each cell line was grown in a recommended medium, McCoy's 5A medium for HCT116 and low glucose Dulbecco's Modified Eagle Medium for MCF7, supplemented with $10 \%$ fetal bovine serum and penicillin/streptomycin solution.

\subsection{Bromodeoxyuridine Incorporation}

HCT116 or MCF7 cells were cultured in 12-well plates $\left(3 \times 10^{4}\right.$ per well) and incubated for $24 \mathrm{~h}$ at $37^{\circ} \mathrm{C}$ in a $5 \% \mathrm{CO}_{2}$ incubator. After $24 \mathrm{~h}$, cells were treated with bromodeoxyuridine (BrdU, Sigma-Aldrich, MO, USA). The extent of BrdU incorporation in cells was examined using a fluorescence microscope (Nikon, Melville, NY, U.S.A) after mounting with DAPI [2]. BrdU positive cells were counted with ImageJ software (National Institutes of Health, Bethesda, MD, USA).

\subsection{Senescence-Associated $\beta$-Galactosidase Assay}

The amounts of SA- $\beta$-gal in Sen-HCT116 and Sen-MCF7 cells for 5 days were determined according to the method of Dimri et al [25]. Cells were examined using the fluorescence microscope after mounting with DAPI [2]. SA- $\beta$-gal positive cells were counted with ImageJ software.

\subsection{MTT [3-(4,5-dimethylthiazol-2-yl)-2,5-diphenyltetrazolium bromide] Assay}

The $\mathrm{IC}_{50}$ of TQ and COS were determined by seeding of HCT116 or MCF7 cells in 12-well plates $\left(3 \times 10^{4}\right.$ per well) and incubated for $24 \mathrm{~h}$ at $37^{\circ} \mathrm{C}$ in a $5 \% \mathrm{CO}_{2}$ incubator. At day 5 of $100 \mathrm{nM}$ Dox treatment, cells were treated with TQ $(0,5,10,25,50,60,75$, or $100 \mu \mathrm{M}$ dissolved in DMSO) or COS $(0,10,25,50,75,100$, or $200 \mu \mathrm{M}$ dissolved in DMSO), incubated for $24 \mathrm{~h}$, and then treated with MTT reagent $(1.25 \mathrm{mg} / \mathrm{ml})$ and incubated for $2 \mathrm{~h}$. The resulting formazan crystals were dissolved in $1 \mathrm{ml}$ DMSO and the optical density was determined using a microplate reader at $570 \mathrm{~nm}$ [2].

\subsection{Flow Cytometric Assessment}

HCT116 or MCF7 cell lines were cultured in T25 flasks ( $30 \times 10^{4}$ cells per flask) for $24 \mathrm{~h}$ and then treated with $10 \mathrm{ml}$ of TQ (50 $\mu \mathrm{M})$ or $\operatorname{COS}(30 \mu \mathrm{M})$ in each flask for proliferative cells. For Sen-cells, the same counts of cells were cultured and treated with 100 $\mathrm{nM}$ of Dox $(10 \mathrm{ml})$ for 5 days after which $10 \mathrm{ml}$ of TQ $(50 \mu \mathrm{M})$ or COS $(30 \mu \mathrm{M})$ were added. Treated cells with their corresponding control flasks were trypsinized, washed with PBS and suspended in $70 \%$ ethanol until flow cytometry assessment of senescence (p53 and p21), apoptotic (Bax), and anti-apoptotic (Bcl2) protein markers using a BD Accuri C6 Plus flow cytometer (Becton Dickinson, San Jose, CA, USA). Cells were treated with FITC-conjugated and mouse-raised anti-p53 (Cat \# 554298), anti-p21 (Cat \# 612236), and anti-Bcl2 (Cat \# 340650) produced by Becton Dickinson and anti-Bax (Cat \# sc-7480) produced by Santa Cruz Biotechnology (Dallas, TX, USA) . Data were analyzed using Accuri C6 software.

\subsection{Reverse Transcription Polymerase Chain Reaction (RT-PCR)}

HCT116 or MCF7 cell lines either proliferative or senescent were cultured in T25 flasks and treated the same way as in the flow cytometry assessment. Total RNA in pelleted cells was extracted using a Total RNA Extraction Kit (iNtRON Biotechnology, Inc., Gyeonggi-do, South Korea). cDNA reverse transcription of the extracted $1 \mu \mathrm{g}$ of RNA was performed with a TIANScript RT Kit (Tiangen, Shanghai, China). RT-PCR was performed with iCycler-iQ Optical System Software version 3.0 A (Bio-Rad, CA, USA). The following primers were used for the quantitative RT-PCR analysis: for caspase 3 (forward): CATGGAAGCGAATCAATGGACT and reverse: CTGTACCAGACCGAGATGTCA, and the housekeeping GAPDH forward primer sequence is GAAGGTGAAGGTCGGAGTCA and the reverse sequence is TTGAGGTCAATGAAGGGGTC.

PCR amplification was done with RealMOD ${ }^{\text {Tm }}$ Green FAST qPCR Master Mix (S) (Tiangen) using the following conditions: 1 cycle at $95^{\circ} \mathrm{C}$ for $30 \mathrm{~s}, 40$ cycles at $95^{\circ} \mathrm{C}$ for $5 \mathrm{~s}, 1$ cycle at $95^{\circ} \mathrm{C}$ for $5 \mathrm{~s}$. The relative mRNA expression levels of caspase 3 gene were calculated using the comparative (Ct) method [26].

\subsection{Statistical Analysis}


Statistical analyses were done with GraphPad Prism 5 (San Diego, CA, USA) using One-way ANOVA (Tukey's Multiple Comparison Test). The $\mathrm{IC}_{50}$ values were determined with nonlinear regression using log (inhibitor) vs. response-variable slope equation. Data are presented as a mean \pm SD. A value of $P<0.05$ was considered statistically significant. All data show the mean results from at least three independent experiments.

\section{Results}

\subsection{Senescence Markers}

Senescence markers of HCT116 cells treated with $100 \mathrm{nM}$ of Dox are illustrated in Figure 1A-1B. HCT116 treated with Dox for 5 consecutive days exhibited significant increases $(P \otimes 0.001)$ in SA- $\beta$-gal positive cells at day 1 (day 1 after Dox treatment of HCT116, Dox 1) and day 5 (day 5 after Dox treatment of HCT116, Dox 5) in comparison with Dox 0 (control, Dox-untreated HCT116). Also, at day 5, SA- $\beta$-gal positive cells were significantly increased $(P \otimes 0.001)$ compared with Dox 1.

BrdU incorporation in Sen-HCT116 cells significantly decreased $(P \otimes 0.001)$ at days 2 and 5 in comparison with Dox 0 (Figure 1C, 1D). Incorporation of BrdU in Sen-HCT116 cells was significantly decreased ( $P \otimes 0.001)$ on day 5 compared with day 1.

The percentages of SA- $\beta$-gal positive cells indicates the extent of accumulation SA- $\beta$-gal in senescent cells that leads to enlargement of the senescent cells, and the percentages of BrdU positive cells at Dox 5 of the senescent cells is low due to the low cell division extent.

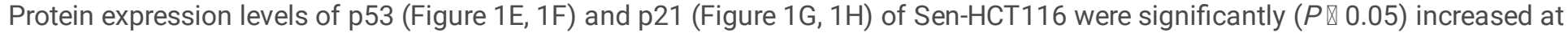
day 1 of Dox treatment of HCT116 compared with control.

Sen-MCF7 exhibited the same extent of senescent markers as Sen-HCT116 regarding SA- $\beta$-gal positive and BrdU incorporation in cells (Figure 2A-2D). The expression of p53 monitored with flow cytometry was significantly increased at day $1(P \otimes 0.05)$ and day $5(P \otimes 0.01)$ compared with Dox 0 (Figure $2 \mathrm{E}, 2 \mathrm{~F})$. Also, the p21 expression was significantly $(P \otimes 0.01)$ increased at day 1 and day 5 compared with Dox 0 (Figure 2G, 2H).

\section{2 $\mathrm{IC}_{50}$ of Thymoquinone and Costunolide}

The IC $\mathrm{I}_{50}$ of TQ against HCT116 is $64.15 \pm 2.80 \mu \mathrm{M}$ (Figure 3A) and $36.95 \pm 6.09 \mu \mathrm{M}$ against MCF7 (Figure 3B), and the IC $\mathrm{C}_{50}$ of COS against HCT116 is $32.08 \pm 0.86 \mu \mathrm{M}$ (Figure $4 \mathrm{~A}$ ) and $40.84 \pm 1.89 \mu \mathrm{M}$ against MCF7 (Figure 4B).

\subsection{Caspase 3}

Relative expression folds of caspase 3 mRNA of Sen-HCT116 with Dox for 5 days then treated with $50 \mu \mathrm{M}$ of TQ for $24 \mathrm{~h}$ (HCT116+Dox5+TQ) were significantly increased ( $P \otimes 0.001)$ compared with control (untreated proliferative HCT116), Dox5, and HCT116+TQ (untreated proliferative HCT116 then treated with $50 \mu \mathrm{M}$ of TQ) (Figure 3C).

Regarding MCF7, the relative expression folds of caspase 3 mRNA were significantly $(P \square 0.01)$ increased in MCF7+TQ (untreated proliferative MCF7 then treated with $50 \mu \mathrm{M}$ of TQ for $24 \mathrm{~h}$ ) and MCF7+Dox5+TQ (Sen-MCF7 with Dox for 5 days and then treated with $50 \mu \mathrm{M}$ of TQ for $24 \mathrm{~h}$ ) compared with control (untreated proliferative MCF7). Cells in the MCF7+Dox5+TQ group exhibited significant increases $(P \otimes 0.05)$ in caspase 3 expression in comparison with Dox5, while Dox5 expressed significant decreases $(P$ $\triangle 0.05$ ) in caspase 3 gene compared with MCF7+TQ (Figure 3D).

In the same manner, $30 \mu \mathrm{M}$ of COS significantly increased $(P \otimes 0.01)$ the relative expression fold change levels of caspase 3 mRNA in Sen-HCT116 in comparison with control (untreated proliferative HCT116), Dox5, and HCT116+TQ (Figure 4C).

\subsection{Bax and Bcl2 Proteins}

Bax protein levels of HCT116 either proliferative or senescent are presented in Figure 5A, 5B. Bax levels were significantly decreased $(P \otimes 0.05)$ in Dox5, while significantly increased $(P \otimes 0.01)$ in HCT116+Dox5+TQ compared with control. Also, its 
expressions were significantly increased in HCT116+Dox5+TQ compared with Dox5 and HCT116+TQ.

Bcl2 protein levels were significantly increased in Dox5 $(P \otimes 0.001)$ and HCT116+Dox5+TQ $(P \otimes 0.01)$ compared with control. In the HCT116+Dox5+TQ cells, Bcl2 protein levels were significantly increased ( $P \otimes 0.01)$ compared with HCT116+TQ and significantly decreased $(P \otimes 0.01)$ compared with Dox5 (Figure 5C, 5D).

Figure 5E and 5F show significant increases $(P<0.01)$ in Bax levels in MCF7+TQ, Dox5, and MCF7+Dox5+TQ compared with control.

In comparison with control MCF7, Bcl2 protein levels were significantly decreased $(P<0.01)$ in MCF7+TQ and significantly increased in Dox5 $(P<0.001)$ and MCF7+Dox5+TQ $(P<0.01)$ as shown in Figure 5G, 5H. Also, Bcl2 levels in Dox5 and MCF7+Dox5+TQ were significantly increased $(P<0.001)$ in comparison with MCF7+TQ. MCF7+Dox5+TQ exhibited significant reduction $(P<0.001)$ in $\mathrm{Bcl} 2$ levels compared with Dox5.

Results in Figure 6 represents the effect of COS $(30 \mu \mathrm{M})$ on proliferative HCT116, proliferative MCF7, Sen-HCT116, and SenMCF7. Bax levels were significantly decreased $(P \otimes 0.05)$ in Dox5 and increased $(P<0.001)$ in HCT116+Dox5+COS compared with control. In the HCT116+Dox5+COS, Bax levels were significantly increased $(P<0.001)$ compared with Dox5 and HCT116+COS (Figure 6A, 6B). In the same cell line, Bcl2 levels were significantly increased $(P<0.001)$ in Dox5 and HCT116+Dox5+COS compared with control and HCT116+COS (Figure 6C, 6D).

In MCF7, the Bax levels were significantly increased $(P<0.05)$ in Dox5 compared with HCT116+COS (Figure 6E, 6F). Bcl2 levels were significantly increased $(P<0.001)$ in Dox5 and HCT116+Dox5+COS compared with control and HCT116+COS. The HCT116+Dox5+COS exhibited significant decreases $(P<0.001)$ in Bcl2 in comparison with Dox5.

When the data of each cell line was calculated to their corresponding control of either proliferative or senescent cells (Table 1), TQ $(50 \mu \mathrm{M})$ significantly increased $(P<0.001)$ Bax and significantly decreased $(P<0.001)$ Bcl2 in Sen-HCT116 and consequently increased Bax/Bcl2 ratio in Sen-HCT116 (1.72). TQ by the same concentration significantly increased $(P<0.001)$ Bax and significantly decreased $(P<0.001) \mathrm{Bcl} 2$ in MCF7+TQ compared with control, while in Sen-MCF7, TQ significantly decreases $(P<$ 0.001) Bcl2 compared with Dox5. Therefore, the Bax/Bcl2 ratio in proliferative and Sen-MCF7 were increased 1.69 and 1.33, respectively, compared with their corresponding control. From these results we can conclude that TQ $(50 \mu \mathrm{M})$ induced apoptosis in both proliferative and Sen-MCF7 especially in proliferative MCF7 that exhibited greater Bax/Bcl2 ratio than Sen-MCF7.

By the same approach, $30 \mu \mathrm{M}$ of COS significantly increased $(P<0.001)$ Bax in HCT116+Dox5+COS and significantly decreased $(P<0.001) \mathrm{Bcl} 2$ of MCF7+Dox5+COS compared with corresponding Dox5 (Table 2). Concomitantly, the Bax/Bcl2 ratios were increased in Sen-HCT116 (1.86) and Sen-MCF7 (1.14) compared with proliferative cells.

Table 1. Percentages of Bcl2-associated X protein (Bax) and B-cell lymphoma 2 (Bcl2) protein levels to their corresponding control of either proliferative or senescent cells (HCT116 and MCF7) treated with thymoquinone (TQ).

\begin{tabular}{|c|c|c|c|c|c|c|c|c|}
\hline & \multicolumn{4}{|l|}{ HCT116 } & \multicolumn{4}{|l|}{ MCF7 } \\
\hline & \multicolumn{2}{|c|}{ Proliferative } & \multicolumn{2}{|c|}{ Senescence } & \multicolumn{2}{|c|}{ Proliferative } & \multicolumn{2}{|c|}{ Senescence } \\
\hline & Control & HCT116+TQ & Dox5 & HCT116+Dox5+TQ & Control & MCF7+TQ & Dox5 & MCF7+Dox5+TQ \\
\hline Bax & 100 & $100.5 \pm 3.3$ & 100 & $152.4 \pm 0.6^{\star \star \star}$ & 100 & $\begin{array}{l}123.4 \pm \\
1.7 * \star \star\end{array}$ & 100 & $96.3 \pm 3.4$ \\
\hline $\mathrm{Bcl} 2$ & 100 & $101.4 \pm 1.3$ & 100 & $88.4 \pm 0.5^{\star \star \star}$ & 100 & $\begin{array}{l}73.1 \pm \\
0.9 * \star \star\end{array}$ & 100 & 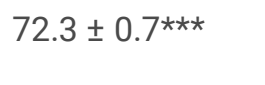 \\
\hline $\begin{array}{l}\mathrm{Bax} / \mathrm{Bcl} 2 \\
\text { ratio }\end{array}$ & 1 & 0.99 & 1 & 1.72 & 1 & 1.69 & 1 & 1.33 \\
\hline
\end{tabular}

Mean \pm SD. 
$* * * P<0.001$ vs. control or Dox5.

Control refers to proliferative-untreated HCT116 or -untreated MCF7. HCT116+TQ refers to HCT116 treated with $50 \mu \mathrm{M}$ TQ for 24 h. MCF7+TQ refers to HCT116 treated with $50 \mu \mathrm{M}$ TQ for 24 h. Dox 5 refers to Sen-HCT116 or Sen-MCF7 with 100 nM Dox for 5 days. HCT116+Dox5+TQ refers to Sen-HCT116 with $100 \mathrm{nM}$ Dox for 5 days then treated with $50 \mu \mathrm{M}$ TQ for 24 h. MCF7+Dox5+TQ refers to Sen-MCF7 with $100 \mathrm{nM}$ Dox for 5 days then treated with $50 \mu \mathrm{M}$ TQ for $24 \mathrm{~h}$.

Table 2. Percentages of Bcl2-associated X protein (Bax) and B-cell lymphoma 2 (Bcl2) protein levels to their corresponding control of either proliferative or senescent cells (HCT116 and MCF7) treated with costunolide (COS).

\begin{tabular}{|c|c|c|c|c|c|c|c|c|}
\hline & \multicolumn{4}{|c|}{ HCT116 } & \multicolumn{4}{|l|}{ MCF7 } \\
\hline & \multicolumn{2}{|c|}{ Proliferative } & \multicolumn{2}{|c|}{ Senescence } & \multicolumn{2}{|c|}{ Proliferative } & \multicolumn{2}{|c|}{ Senescence } \\
\hline & Control & HCT116+COS & Dox5 & HCT116+Dox5+COS & Control & MCF7+COS & Dox5 & MCF7+Dox5+COS \\
\hline Bax & 100 & $99.4 \pm 0.7$ & 100 & $185.7 \pm 0.5^{\star \star \star}$ & 100 & $98.8 \pm 1.4$ & 100 & $89.7 \pm 9.2$ \\
\hline $\mathrm{Bcl} 2$ & 100 & $99.5 \pm 1.1$ & 100 & $99.8 \pm 0.3$ & 100 & $100 \pm 1.1$ & 100 & $78.4 \pm 0.9 * * \star$ \\
\hline $\begin{array}{l}\text { Bax/Bcl2 } \\
\text { ratio }\end{array}$ & 1 & 1 & 1 & 1.86 & 1 & 0.99 & 1 & 1.14 \\
\hline
\end{tabular}

Mean \pm SD.

$\star * \star P<0.001$ vs. control or Dox5.

Control refers to proliferative-untreatedHCT116 or -untreated MCF7. HCT116+COS refers to HCT116 treated with $30 \mu \mathrm{M}$ COS for $24 \mathrm{~h}$. MCF7+COS refers to HCT116 treated with $30 \mu \mathrm{M}$ COS for 24 h. Dox 5 refers to Sen-HCT116 or Sen-MCF7 with $100 \mathrm{nM}$ Dox for 5 days. HCT116+Dox $5+C O S$ refers to Sen-HCT116 with $100 \mathrm{nM}$ Dox for 5 days then treated with $30 \mu \mathrm{M}$ COS for $24 \mathrm{~h}$. MCF7+Dox5+COS refers to Sen-MCF7 with $100 \mathrm{nM}$ Dox for 5 days then treated with $30 \mu \mathrm{M}$ COS for $24 \mathrm{~h}$.

\section{Discussion}

Markers of senescence such as SA- $\beta$-gal and protein levels of p53 and p21 were significantly increased in the Sen-HCT116 and Sen-MCF7 besides significant decreases in BrdU incorporation. The same results were found when HCT116 or MCF7 cell lines were treated with $100 \mathrm{nM}$ of Dox [2, 27, 28]. HCT116 exposed to $50 \mathrm{nM}$ [29-31], $75 \mathrm{nM}$ [32], $100 \mathrm{nM}$ [2, 31, 33-36], and 200 nM [37] for 1-4 days exhibited the features of senescence. Higher doses of Dox induced senescence in HCT116 by doses of $1 \mu \mathrm{M}$ for $2 \mathrm{~h}$ [38] and $500 \mathrm{nM}$ for $4 \mathrm{~h}$ [39]. In the same manner, MCF7 exhibited the senescence feature when subjected to different levels of Dox such as $38 \mathrm{nM}[40], 50 \mathrm{nM}[29,41], 75 \mathrm{nM}[32$, 42], $100 \mathrm{nM}[2,27,28]$, and $500 \mathrm{nM}[43]$ for 1- 5 days. Also, high doses of Dox $1 \mu \mathrm{M}$ [44] and $10 \mu \mathrm{M}$ [45] for $2 \mathrm{~h}$ were used to induce senescence in a short time period. Researchers used either low Dox doses for long periods or high dose for a maximum of $2 \mathrm{~h}$ to enhance the senescence process before induction of cancer cell apoptosis by Dox.

In the above-mentioned studies, Dox induced upregulation of p53, especially the phospho-p53 (Ser15) that consequently, upregulated p21 [2], which induced cell cycle arrest through inhibition of cyclin E/cyclin-dependent kinase 2 (CDK2) and cyclindependent kinase (CDK1) activities [46]. In addition, SA- $\beta$-gal accumulated in the Dox-treated cancer cells, leading to enlargement of cancer cells, and senescent HCT116 cells try to escape from senescence by polyploidization $[2,18]$.

Results of the present study revealed that TQ exhibited $\mathrm{IC}_{50}$ against HCT116 and MCF7, $64.15 \pm 2.80 \mu \mathrm{M}$ and $36.95 \pm 6.09 \mu \mathrm{M}$, respectively, while COS is $32.08 \pm 0.86 \mu \mathrm{M}$ for HCT116 and $40.84 \pm 1.89 \mu \mathrm{M}$ for MCF7. Similarly, Fröhlich et al [47] stated that TQ has $\mathrm{IC}_{50}$ of $50.1 \pm 6.1$ for HCT116 and $42.0 \pm 8.5$ for MCF7. Roy and Manikkam [13] determined the IC ${ }_{50}$ of COS against MCF7 by $40 \mu \mathrm{M}$. 
Caspase 3 is a major executing protein in cellular exposure to cytotoxic medications, radiation therapy or immunotherapy during proteolytic degradation. It is also used as a marker for cancer treatment effectiveness [48]. In the current study, TQ significantly increased caspase 3 in HCT116 + Dox5 + TQ compared with Dox5, while in MCF7 both proliferative and senescent subjected to $50 \mu \mathrm{M}$ of TQ expressed significant increases in caspase 3 compared with their control cells. Numerous published studies revealed significant upregulation in caspase 3 in p53-null myeloblastic leukemia (HL-60) [49], human lung (LNM35) [50], human osteosarcoma (MG63) [51], HCT116 [52], and MCF7 [53] cancer cell lines treated with TQ. Also, COS induced upregulation and activation of caspase 3 in multidrug-resistant ovarian cancer (OAW42) [54] and human gastric (BGC-823) [55] proliferative cancer cell lines.

Bax is a pro-apoptotic protein that is responsible for causing cell death and $\mathrm{Bcl} 2$ is an anti-apoptotic protein that regulates the mitochondrial membrane function and protects cells from apoptosis [56]. Both Bax and Bcl2 are regulated by the tumorsuppressor protein p53 [57]. Therefore, an increased $\mathrm{Bax} / \mathrm{Bcl} 2$ ratio is a factor in predisposing apoptosis [58, 59]. In the current study, Bax levels were significantly increased in HCT116 + Dox 5 + TQ compared with their control senescent (Dox5), and Bcl2 levels were significantly decreased. These data indicate the sensitivity of Sen-HCT116 to TQ-induced apoptosis compared with proliferative HCT116. Also, MCF7 + Dox5 + TQ exhibited significant decreases compared with Dox5 and MCF7 + TQ that favored apoptosis of both Sen-HCT116 and Sen-MCF7. Sensitivity of Sen-HCT116 and Sen-MCF7 to TQ compared with their corresponding proliferative cells has been stated in our previous study [2]. Also, COS induced increases in Bax/Bcl2 ratio in HCT116 + Dox5 + TQ and MCF7 + Dox5 + TQ compared with their corresponding Dox5 cells. These results indicate the sensitivity of both Sen-HCT116 and Sen-MCF7 to COS compared with their corresponding proliferative cells.

\section{Conclusion}

Dox is a commonly used chemotherapeutic agent for cancer treatment and to induce cellular senescence of both HCT116 and MCF7 cell lines. To prevent the relapse of these senescent cells to proliferative cells, we intervened with TQ and COS treatments to rapidly eliminate the senescent cells in comparison with their proliferative cell type. Both TQ and COS induced more apoptosis of Sen-HCT116 and Sen-MCF7 in relation to their proliferative cells by different extents and cell specificity. Based on the current data, we conclude that TQ and COS induced senolysis of Sen-HCT116, and TQ induced apoptosis of both proliferative and SenMCF7. Conversely, COS induced slight apoptosis of Sen-MCF7 more than proliferative. We suggest that future in vivo and clinical trials include either TQ or COS in the Dox treatment schedule of cancer.

\section{Declarations}

Conflicts of interest: The authors declare no conflict of interest.

Funding: This research received no external funding.

Acknowledgments: We appreciate Kelly Keating for her editorial assistance.

Author Contributions: Conceptualization, Ali H. El-Far, Ahmed E. Noreldin and Soad K. Al Jaouni; Data curation, Ali H. El-Far, Soad K. Al Jaouni and Shaker A. Mousa; Formal analysis, Ali H. El-Far and Ahmed E. Noreldin; Funding acquisition, Soad K. Al Jaouni and Shaker A. Mousa; Investigation, Ali H. El-Far and Ahmed E. Noreldin; Methodology, Ali H. El-Far; Project administration, Ali H. El-Far; Resources, Ali H. El-Far, Ahmed E. Noreldin and Shaker A. Mousa; Software, Ali H. El-Far, Ahmed E. Noreldin and Shaker A. Mousa; Supervision, Ali H. El-Far, Soad K. Al Jaouni and Shaker A. Mousa; Validation, Ali H. El-Far; Visualization, Ali H. El-Far; Writing - original draft, Ali H. El-Far; Writing - review \& editing, Ali H. El-Far, Ahmed E. Noreldin, Soad K. Al Jaouni and Shaker A. Mousa.

\section{References}

1. El-Far AH. Thymoquinone Anticancer Discovery: Possible Mechanisms. Curr Drug Discov Technol. 2015;12:80-9.

2. El-Far AH, Darwish NHE, Mousa SA. Senescent Colon and Breast Cancer Cells Induced by Doxorubicin Exhibit Enhanced Sensitivity to Curcumin, Caffeine, and Thymoquinone. Integr Cancer Ther. 2020;19:153473541990116.

Page $7 / 14$ 
doi:10.1177/1534735419901160.

3. Gali-Muhtasib H, Kuester D, Mawrin C, Bajbouj K, Diestel A, Ocker M, et al. Thymoquinone Triggers Inactivation of the Stress Response Pathway Sensor CHEK1 and Contributes to Apoptosis in Colorectal Cancer Cells. Cancer Res. 2008;68:5609-18.

4. Atta MS, El-Far AH, Farrag FA, Abdel-Daim MM, Al Jaouni SK, Mousa SA. Thymoquinone attenuates cardiomyopathy in streptozotocin-treated diabetic rats. Oxid Med Cell Longev. 2018;2018:1-10. doi:10.1155/2018/7845681.

5. El-Far A, Al Jaouni S, Li W, Mousa S. Protective Roles of Thymoquinone Nanoformulations: Potential Nanonutraceuticals in Human Diseases. Nutrients. 2018;10:1369. doi:10.3390/nu10101369.

6. Atta MS, Almadaly EAEA, El-Far AHAH, Saleh RMRM, Assar DHDH, Al Jaouni SKSK, et al. Thymoquinone defeats diabetesinduced testicular damage in rats targeting antioxidant, inflammatory and aromatase expression. Int J Mol Sci. 2017;18:919.

7. Gali-Muhtasib H, Diab-Assaf M, Boltze C, Al-Hmaira J, Hartig R, Roessner A, et al. Thymoquinone extracted from black seed triggers apoptotic cell death in human colorectal cancer cells via a p53-dependent mechanism. Int J Oncol. 2004;25:857-66.

8. Dastjerdi M, Mehdiabady E, Iranpour F, Bahramian H. Effect of thymoquinone on P53 gene expression and consequence apoptosis in breast cancer cell line. Int J Prev Med. 2016;7:66.

9. Woo CC, Hsu A, Kumar AP, Sethi G, Tan KHB. Thymoquinone Inhibits Tumor Growth and Induces Apoptosis in a Breast Cancer Xenograft Mouse Model: The Role of p38 MAPK and ROS. PLoS One. 2013;8:e75356.

10. Kim YE, Choi HC, Nam G, Choi BY. Costunolide promotes the proliferation of human hair follicle dermal papilla cells and induces hair growth in C57BL/6 mice. J Cosmet Dermatol. 2019;18:414-21.

11. Kim DY, Choi BY. Costunolide-A Bioactive Sesquiterpene Lactone with Diverse Therapeutic Potential. Int J Mol Sci. 2019;20:2926. doi:10.3390/ijms20122926.

12. Hua P, Zhang G, Zhang Y, Sun M, Cui R, Li X, et al. Costunolide induces G1/S phase arrest and activates mitochondrialmediated apoptotic pathways in SK-MES 1 human lung squamous carcinoma cells. Oncol Lett. 2016;11:2780-6.

13. Roy A, Manikkam R. Cytotoxic impact of costunolide isolated from Costus speciosus on breast cancer via differential regulation of cell cycle - An in-vitro and in-silico approach. Phyther Res. 2015;29:1532-9.

14. Wang AS, Dreesen O. Biomarkers of cellular senescence and skin aging. Frontiers in Genetics. 2018;9 AUG:247.

15. Debacq-Chainiaux F, Erusalimsky JD, Campisi J, Toussaint O. Protocols to detect senescence-associated beta-galactosidase (SA-Bgal) activity, a biomarker of senescent cells in culture and in vivo. Nat Protoc. 2009;4:1798-806.

16. Chen W, Kang J, Xia J, Li Y, Yang B, Chen B, et al. p53-related apoptosis resistance and tumor suppression activity in UVBinduced premature senescent human skin fibroblasts. Int J Mol Med. 2008;21:645-53. doi:10.3892/ijmm.21.5.645.

17. Qian Y, Chen X. Senescence regulation by the p53 protein family. Methods Mol Biol. 2013;965:37-61.

18. Mosieniak G, Sliwinska MA, Alster O, Strzeszewska A, Sunderland P, Piechota M, et al. Polyploidy Formation in DoxorubicinTreated Cancer Cells Can Favor Escape from Senescence. Neoplasia. 2015;17:882-93.

19. Wang X, Wong SCH, Pan J, Tsao SW, Fung KHY, Kwong DLW, et al. Evidence of cisplatin-induced senescent-like growth arrest in nasopharyngeal carcinoma cells. Cancer Res. 1998;58:5019-22. https://pubmed.ncbi.nlm.nih.gov/9823301/. Accessed 9 Jul 2020.

20. Chang BD, Broude E V., Dokmanovic M, Zhu H, Ruth A, Xuan Y, et al. A senescence-like phenotype distinguishes tumor cells that undergo terminal proliferation arrest after exposure to anticancer agents. Cancer Res. 1999.

21. Demaria M, O'Leary MN, Chang J, Shao L, Liu S, Alimirah F, et al. Cellular Senescence Promotes Adverse Effects of Chemotherapy and Cancer Relapse. Cancer Discov. 2017;7:165-76. doi:10.1158/2159-8290.CD-16-0241.

22. Tacar O, Sriamornsak P, Dass CR. Doxorubicin: an update on anticancer molecular action, toxicity and novel drug delivery systems. J Pharm Pharmacol. 2013;65:157-70.

23. Milczarek M. The Premature Senescence in Breast Cancer Treatment Strategy. Cancers (Basel). 2020;12:1815. doi:10.3390/cancers12071815.

24. Bavik C, Coleman I, Dean JP, Knudsen B, Plymate S, Nelson PS. The gene expression program of prostate fibroblast senescence modulates neoplastic epithelial cell proliferation through paracrine mechanisms. Cancer Res. 2006. 
25. Dimri GP, Lee X, Basile G, Acosta M, Scott G, Roskelley C, et al. A biomarker that identifies senescent human cells in culture and in aging skin in vivo. Proc Natl Acad Sci U S A. 1995;92:9363-7. http://www.ncbi.nlm.nih.gov/pubmed/7568133. Accessed 16 Dec 2018.

26. Schmittgen TD, Livak KJ. Analyzing real-time PCR data by the comparative CT method. Nat Protoc. 2008;3:1101-8.

27. Taylor JR, Lehmann BD, Chappell WH, Abrams SL, Steelman LS, McCubrey JA. Cooperative effects of Akt-1 and Raf-1 on the induction of cellular senescence in doxorubicin or tamoxifen treated breast cancer cells. Oncotarget. 2011;2:610-26.

28. Basu A, Pal D, Blaydes R. Differential effects of protein kinase C-eta on apoptosis versus senescence. Cell Signal. 2019;55:17. doi:10.1016/j.cellsig.2018.12.003.

29. Shao AW, Sun H, Geng Y, Peng Q, Wang P, Chen J, et al. Bclaf1 is an important NF-KB signaling transducer and C/EBP $\beta$ regulator in DNA damage-induced senescence. Cell Death Differ. 2016;23:865-75.

30. Chang BD, Xuan Y, Broude E V., Zhu H, Schott B, Fang J, et al. Role of p53 and p21(waf1/cip1) in senescence-like terminal proliferation arrest induced in human tumor cells by chemotherapeutic drugs. Oncogene. 1999;18:4808-18.

31. Drummond CJ, Finlay GJ, Broome L, Marshall ES, Richardson E, Baguley BC. Action of SN 28049, a new DNA binding topoisomerase II-directed antitumour drug: Comparison with doxorubicin and etoposide. Invest New Drugs. 2011;29:110210.

32. Di X, Bright AT, Bellott R, Gaskins E, Robert J, Holt S, et al. A chemotherapy-associated senescence bystander effect in breast cancer cells. Cancer Biol Ther. 2008;7:682-90.

33. Strzeszewska A, Alster O, Mosieniak G, Ciolko A, Sikora E. Insight into the role of PIKK family members and NF-kB in DNAdamage-induced senescence and senescence-associated secretory phenotype of colon cancer cells. Cell Death Dis. 2018;9:44. doi:10.1038/s41419-017-0069-5.

34. Sliwinska MA, Mosieniak G, Wolanin K, Babik A, Piwocka K, Magalska A, et al. Induction of senescence with doxorubicin leads to increased genomic instability of HCT116 cells. Mech Ageing Dev. 2009;130:24-32.

35. Tong Y, Zhao W, Zhou C, Wawrowsky K, Melmed S. PTTG1 Attenuates Drug-Induced Cellular Senescence. PLoS One. 2011;6:e23754. doi:10.1371/journal.pone.0023754.

36. Was H, Barszcz K, Czarnecka J, Kowalczyk A, Bernas T, Uzarowska E, et al. Bafilomycin A1 triggers proliferative potential of senescent cancer cells in vitro and in NOD/SCID mice. Oncotarget. 2017;8:9303-22.

37. Chang BD, Swift ME, Shen M, Fang J, Broude E V., Roninson IB. Molecular determinants of terminal growth arrest induced in tumor cells by a chemotherapeutic agent. Proc Natl Acad Sci U S A. 2002;99:389-94.

38. Saleh T, Tyutyunyk-Massey L, Murray GF, Alotaibi MR, Kawale AS, Elsayed Z, et al. Tumor cell escape from therapy-induced senescence. Biochem Pharmacol. 2019;162:202-12. doi:10.1016/j.bcp.2018.12.013.

39. Tato-Costa J, Casimiro S, Pacheco T, Pires R, Fernandes A, Alho I, et al. Therapy-induced cellular senescence induces epithelial-to-mesenchymal transition and increases invasiveness in rectal cancer. Clin Colorectal Cancer. 2016;15:170-178.e3.

40. Lee SLO, Hong SW, Shin JS, Kim JS, Ko SG, Hong NJ, et al. p34SEl-1 inhibits doxorubicin-induced senescence through a pathway mediated by protein kinase $\mathrm{C}-\delta$ and c-Jun-NH2-kinase 1 activation in human breast cancer MCF7 cells. Mol Cancer Res. 2009;7:1845-53.

41. Srdic-Rajic T, Santibañez JF, Kanjer K, Tisma-Miletic N, Cavic M, Galun D, et al. Iscador Qu inhibits doxorubicin-induced senescence of MCF7 cells. Sci Rep. 2017;7:3763. doi:10.1038/s41598-017-03898-0.

42. Di X, Shiu RP, Newsham IF, Gewirtz DA. Apoptosis, autophagy, accelerated senescence and reactive oxygen in the response of human breast tumor cells to Adriamycin. Biochem Pharmacol. 2009;77:1139-50.

43. Huun J, Lønning PE, Knappskog S. Effects of concomitant inactivation of p53 and pRb on response to doxorubicin treatment in breast cancer cell lines. Cell Death Discov. 2017;3:17026. doi:10.1038/cddiscovery.2017.26.

44. Jackson JG, Pereira-Smith OM. Primary and Compensatory Roles for RB Family Members at Cell Cycle Gene Promoters That Are Deacetylated and Downregulated in Doxorubicin-Induced Senescence of Breast Cancer Cells. Mol Cell Biol. 2006;26:2501-10.

45. Elmore LW, Rehder CW, Di X, McChesney PA, Jackson-Cook CK, Gewirtz DA, et al. Adriamycin-induced Senescence in Breast Tumor Cells Involves Functional p53 and Telomere Dysfunction. J Biol Chem. 2002;277:35509-15. 
46. Bunz F. Requirement for p53 and p21 to Sustain G2 Arrest After DNA Damage. Science (80- ). 1998;282:1497-501. doi:10.1126/science.282.5393.1497.

47. Fröhlich T, Ndreshkjana B, Muenzner JK, Reiter C, Hofmeister E, Mederer S, et al. Synthesis of Novel Hybrids of Thymoquinone and Artemisinin with High Activity and Selectivity Against Colon Cancer. ChemMedChem. 2017;12:226-34. doi:10.1002/cmdc.201600594.

48. Zhou M, Liu X, Li Z, Huang Q, Li F, Li CY. Caspase-3 regulates the migration, invasion and metastasis of colon cancer cells. Int J Cancer. 2018;143:921-30.

49. El-Mahdy MA, Zhu Q, Wang QE, Wani G, Wani AA. Thymoquinone induces apoptosis through activation of caspase-8 and mitochondrial events in p53-null myeloblastic leukemia HL-60 cells. Int J Cancer. 2005;117:409-17.

50. Attoub S, Sperandio O, Raza H, Arafat K, Al-Salam S, Al Sultan MA, et al. Thymoquinone as an anticancer agent: evidence from inhibition of cancer cells viability and invasion in vitro and tumor growthin vivo. Fundam Clin Pharmacol. 2013;27:55769.

51. Roepke M, Diestel A, Bajbouj K, Walluscheck D, Schonfeld P, Roessner A, et al. Lack of p53 augments thymoquinone-induced apoptosis and caspase activation in human osteosarcoma cells. Cancer Biol Ther. 2007;6:160-9.

52. Kundu J, Choi BY, Jeong C-H, Kundu JK, Chun K-S. Thymoquinone induces apoptosis in human colon cancer HCT116 cells through inactivation of STAT3 by blocking JAK2- and Src-mediated phosphorylation of EGF receptor tyrosine kinase. Oncol Rep. 2014;32:821-8.

53. Aslan M, Afşar E, Kırımlıoglu E, Çeker T, Yılmaz Ç. Antiproliferative Effects of Thymoquinone in MCF-7 Breast and HepG2 Liver Cancer Cells: Possible Role of Ceramide and ER Stress. Nutr Cancer. 2020;:1-13. doi:10.1080/01635581.2020.1751216.

54. Fang Y, Li J, Wu Y, Gui J, Shen Y. Costunolide inhibits the growth of OAW42-a multidrug-resistant human ovarian cancer cells by activating apoptotic and autophagic pathways, production of reactive oxygen species (ROS), cleaved caspase-3 and cleaved caspase-9. Med Sci Monit. 2019;25:3231-7.

55. Yan Z, Xu T, An Z, Hu Y, Chen W, Ma J, et al. Costunolide induces mitochondria-mediated apoptosis in human gastric adenocarcinoma BGC-823 cells. BMC Complement Altern Med. 2019;19:151. doi:10.1186/s12906-019-2569-6.

56. Wang C, Youle RJ. The Role of Mitochondria. Annu Rev Genet. 2009;43:95-118. doi:10.1146/annurev-genet-102108-134850.

57. Srinivas G, Panicker KR, Pillai MR, Kusumakumary P, Nair MK. Mutant p53 protein, Bcl-2/Bax ratios and apoptosis in paediatric acute lymphoblastic leukaemia. J Cancer Res Clin Oncol. 2000;126:62-7.

58. Argiris A, Cohen E, Karrison T, Esparaz B, Mauer A, Ansari R, et al. A phase II trial of perifosine, an oral alkylphospholipid, in recurrent or metastatic head and neck cancer. Cancer Biol Ther. 2006;5:766-70.

59. Vaskivuo TE, Stenbäck F, Karhumaa P, Risteli J, Dunkel L, Tapanainen JS. Apoptosis and apoptosis-related proteins in human endometrium. Mol Cell Endocrinol. 2000;165:75-83.

\section{Figures}




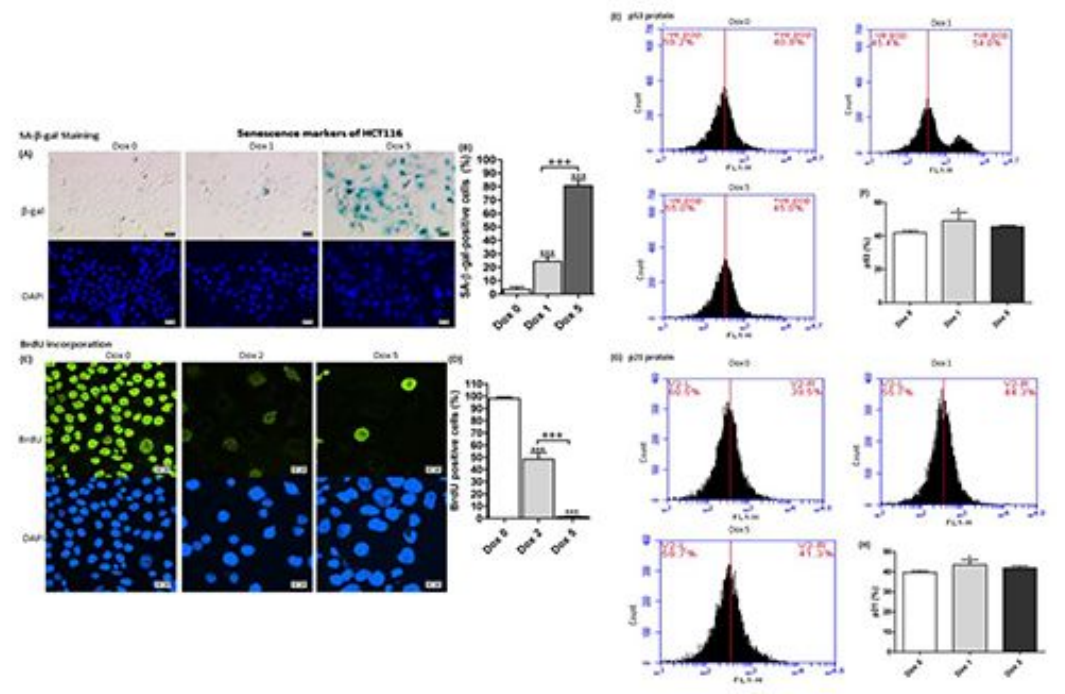

Figure 1

Senescence markers of Sen-HCT116. (A) SA- $\beta$-gal-positive cells of Sen-HCT116 cells. Scale bar is $50 \mu m$. (B) SA- $\beta$-gal-positive cells percentages. (C) BrdU incorporation for Sen-HCT116 cells. Magnification 200x. Scale bar is $50 \mu \mathrm{m}$. (D) BrdU positive cells percentages. (E) p53 protein expressions by flow cytometry of Sen-HCT116 cells. (F) p53 protein expression percentages. (G) p21 protein expressions by flow cytometry of Sen-HCT116 cells. (H) p21 protein expression percentages. The data were analyzed with One-way ANOVA (Tukey's Multiple Comparison Test). Error bars represent mean $\pm \mathrm{SD}$. ${ }^{*} \mathrm{P}<0.05$ and ${ }^{\star \star \star} \mathrm{P}<0.001$ vs. Day 0 (control). $+++P<0.001$ vs. Dox 1 (SA- $\beta$-gal) and Dox 2 (BrdU). Dox 0 refers to untreated cells. Dox 1 refers to day 1 after Dox treatment. Dox 5 refers to day 5 after Dox treatment.
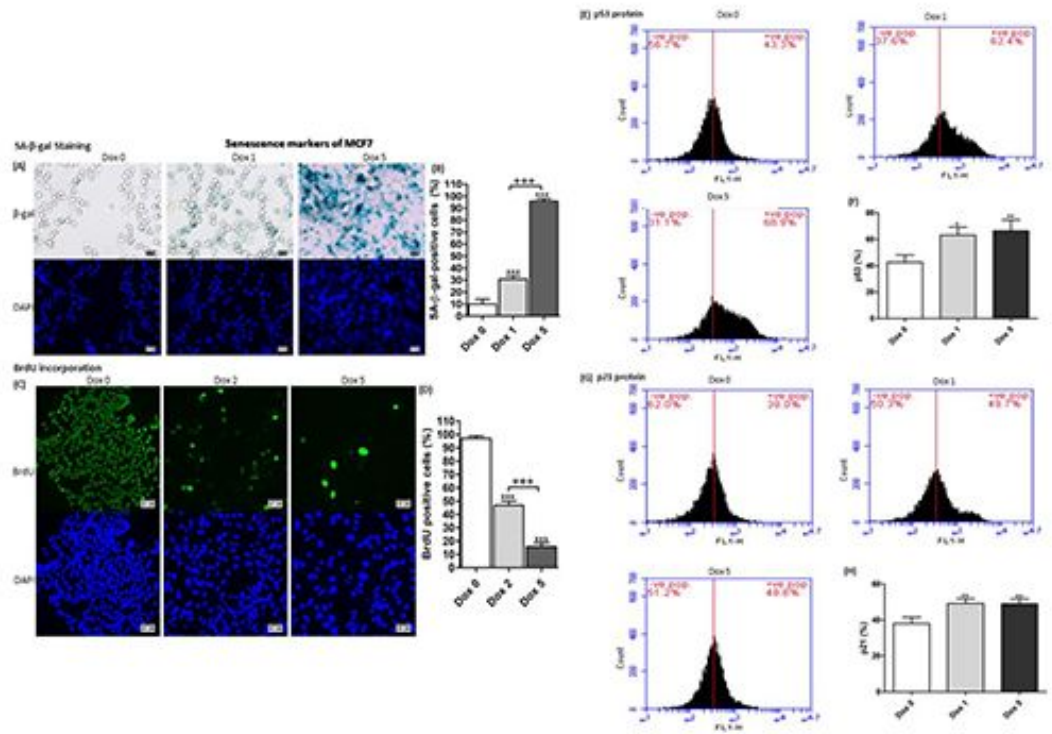

Figure 2

Senescence markers of Sen-MCF7. (A) SA- $\beta$-gal-positive cells of Sen-MCF7 cells. Scale bar is $50 \mu \mathrm{m}$. (B) SA- $\beta$-gal-positive cells percentages. (C) BrdU incorporation for Sen-MCF7 cells. Magnification 200x. Scale bar is $50 \mu \mathrm{m}$. (D) BrdU positive cells percentages. (E) p53 protein expressions by flow cytometry of Sen-HCT116 cells. (F) p53 protein expression percentages. (G) p21 protein expressions by flow cytometry of Sen-HCT116 cells. (H) p21 protein expression percentages. The data were analyzed with One-way ANOVA (Tukey's Multiple Comparison Test). Error bars represent mean $\pm \mathrm{SD}$. ${ }^{\mathrm{P}}<0.05, * \star \mathrm{P}<0.01$, and $* \star * \mathrm{P}<0.001$ vs. 
Day 0 (control). +++P $<0.001$ vs. Dox 1 (SA- $\beta$-gal) and Dox 2 (BrdU). Dox 0 refers to untreated cells. Dox 1 refers to day 1 after Dox treatment. Dox 5 refers to day 5 after Dox treatment.

(A) HCT116

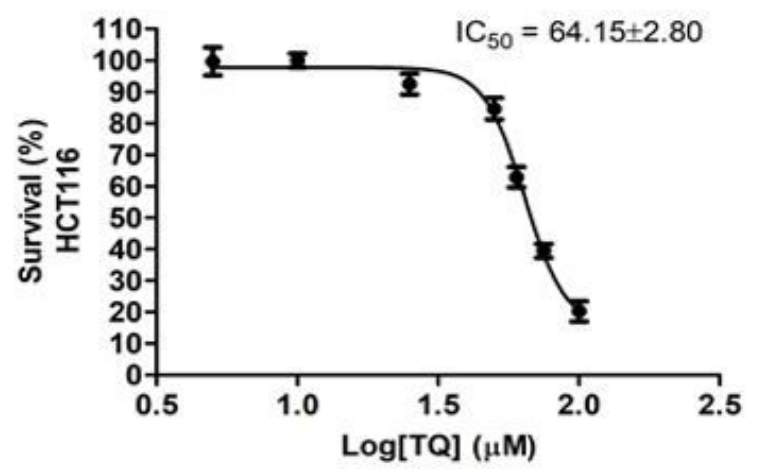

(C) HCT116

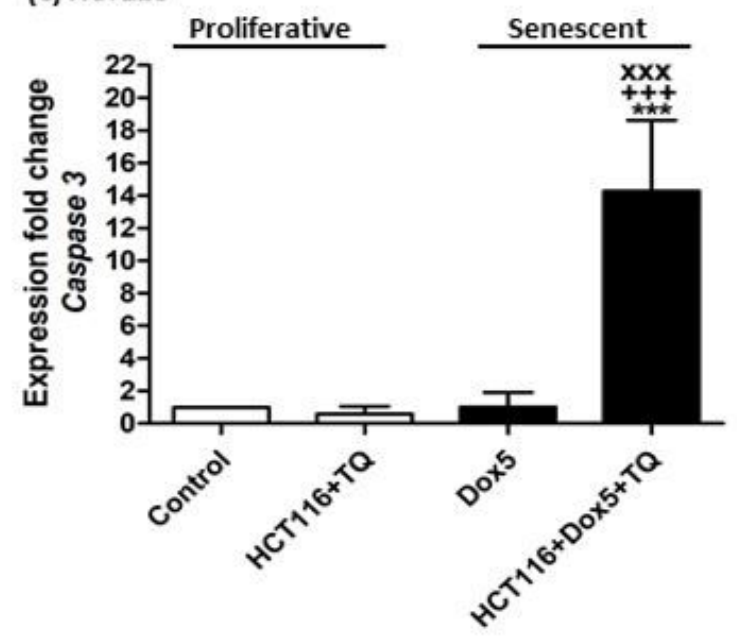

(B) MCF7

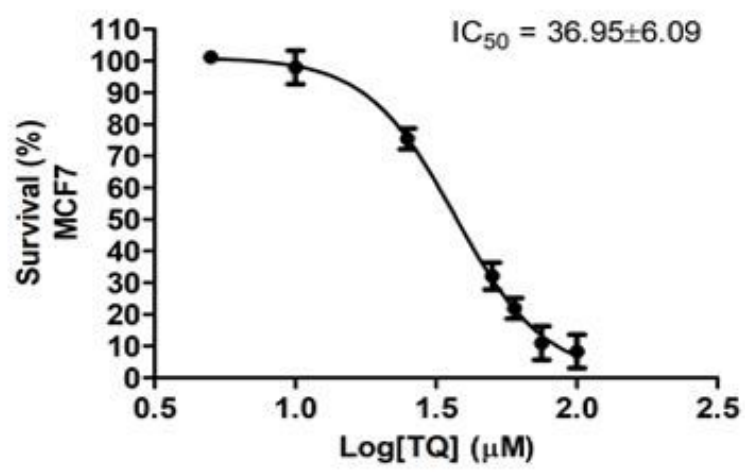

(D) MCF7

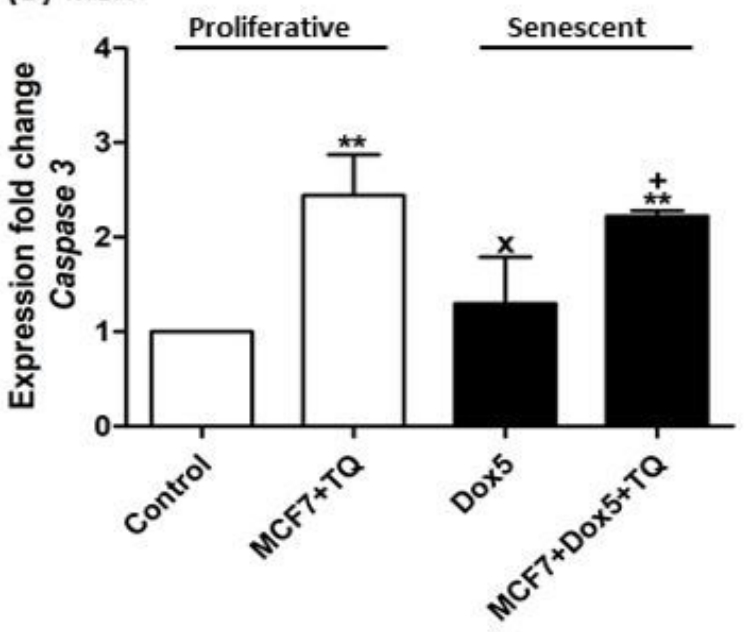

Figure 3

IC50 values of thymoquinone (TQ) against (A) HCT116 and (B) MCF7. (C) Caspase 3 mRNA relative fold changes in Sen-HCT116. (D) Caspase 3 mRNA relative fold changes in Sen-MCF7. Error bars represent mean $\pm S D$. ${ }^{*} P<0.01$ and ${ }^{* \star *} P<0.001$ vs. control. $+P<0.05$ and $+++P<0.001$ vs. Dox5. xP $<0.05$ and xxxP $<0.001$ vs. HCT116+TQ or MCF7+TQ. Control refers to proliferativeuntreated HCT116 or -untreated MCF7. HCT116+TQ refers to HCT116 treated with $50 \mu \mathrm{M}$ TQ for $24 \mathrm{~h}$. MCF7+TQ refers to HCT116 treated with $50 \mu \mathrm{M}$ TQ for 24 h. Dox 5 refers to Sen-HCT116 or Sen-MCF7 with $100 \mathrm{nM}$ Dox for 5 days. HCT116+Dox5+TQ refers to Sen-HCT116 with $100 \mathrm{nM}$ Dox for 5 days then treated with $50 \mu \mathrm{M}$ TQ for 24 h. MCF7+Dox5+TQ refers to Sen-MCF7 with $100 \mathrm{nM}$ Dox for 5 days then treated with $50 \mu \mathrm{M}$ TQ for $24 \mathrm{~h}$. 

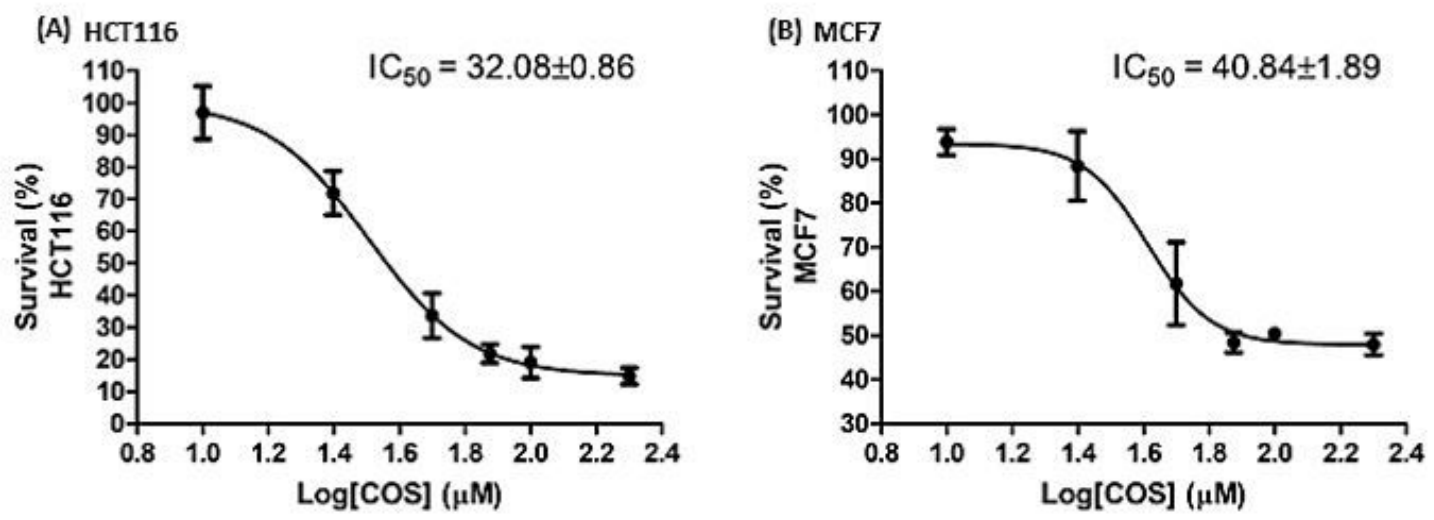

(C) HCT116

(D) MCF7
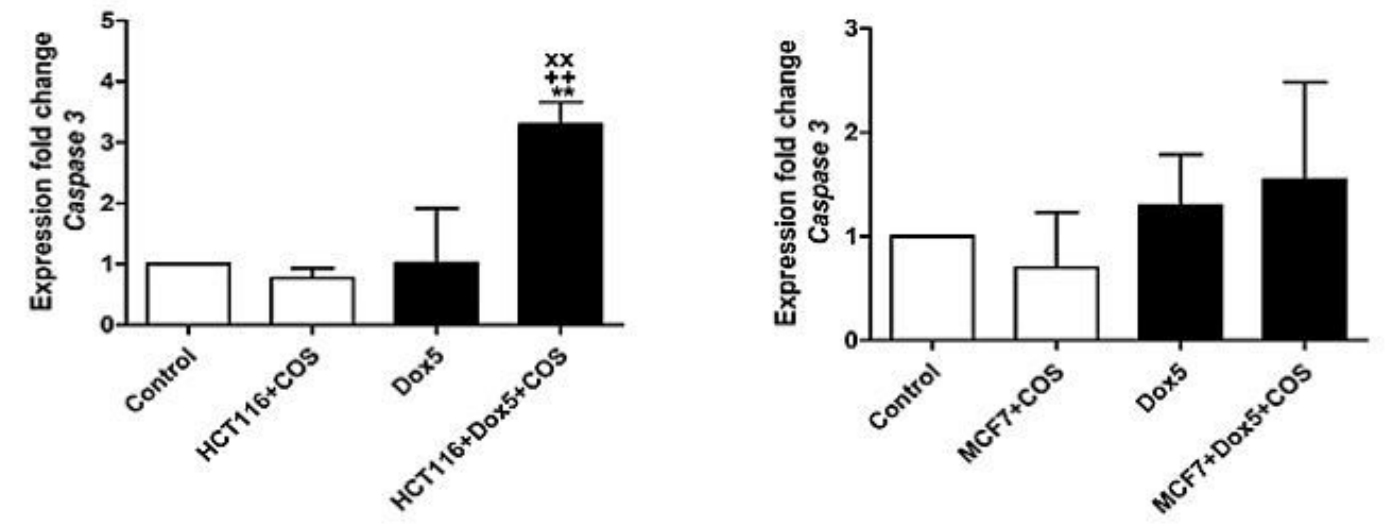

Figure 4

IC50 values of costunolide (COS) against (A) HCT116 and (B) MCF7. (C) Caspase 3 mRNA relative fold changes in Sen-HCT116. (D) Caspase 3 mRNA relative fold changes in Sen-MCF7. Error bars represent mean \pm SD. ${ }^{*} P<0.01$ vs. control. $++P<0.01$ vs. Dox5. xxP $<0.01$ vs. HCT116+COS or MCF7+COS. Control refers to proliferative-untreated HCT116 or -untreated MCF7. HCT116+COS refers to HCT116 treated with $30 \mu \mathrm{M}$ COS for $24 \mathrm{~h}$. MCF7+COS refers to HCT116 treated with $30 \mu \mathrm{M}$ COS for $24 \mathrm{~h}$. Dox5 refers to Sen-HCT116 or Sen-MCF7 with 100 nM Dox for 5 days. HCT116+Dox5+COS refers to Sen-HCT116 with 100 nM Dox for 5 days then treated with $30 \mu \mathrm{M}$ COS for 24 h. MCF7+Dox5+COS refers to Sen-MCF7 with 100 nM Dox for 5 days then treated with $30 \mu \mathrm{M}$ COS for $24 \mathrm{~h}$.
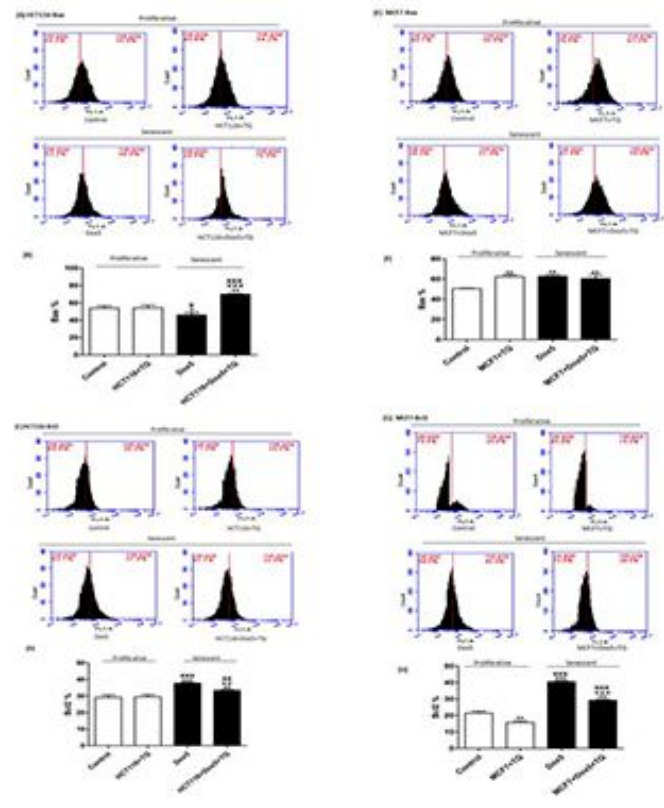
Figure 5

Bax and Bcl2 protein expressions of proliferative HCT116, Sen-HCT116, and proliferative MCF7, Sen-MCF7 cells by flow cytometry. (A) Bcl2-associated X protein (Bax) protein levels of proliferative and Sen-HCT116. (B) Percentages of Bax protein levels of proliferative and Sen-HCT116. (C) B-cell lymphoma 2 (Bcl2) protein levels of proliferative and Sen-HCT116. (D) Percentages of Bcl2 protein levels of proliferative and Sen-HCT116. (E) Bax protein levels of proliferative and Sen-MCF7. (F) Percentages of Bax protein levels of proliferative and Sen-MCF7. (G) Bcl2 protein levels of proliferative and Sen-MCF7. (H) Percentages of Bcl2 protein levels of proliferative and Sen-MCF7. The data were analyzed with One-way ANOVA (Tukey's Multiple Comparison Test). Error bars represent mean \pm SD. ${ }^{*} P<0.05$, ${ }^{*} P<0.01$, and ${ }^{*} * * P<0.001$ vs. control. $++P<0.01$ and $+++P<$ 0.001 vs. Dox5. xP $<0.05, x x P<0.01$, and xxxP $<0.001$ vs. HCT116+TQ or MCF7+TQ. Control refers to proliferative-untreated HCT116 or -untreated MCF7. HCT116+TQ refers to HCT116 treated with $50 \mu \mathrm{M} \mathrm{TQ}$ for $24 \mathrm{~h}$. MCF7+TQ refers to HCT116 treated with $50 \mu \mathrm{M}$ TQ for $24 \mathrm{~h}$. Dox 5 refers to Sen-HCT116 or Sen-MCF7 with $100 \mathrm{nM}$ Dox for 5 days. HCT116+Dox5+TQ refers to SenHCT116 with $100 \mathrm{nM}$ Dox for 5 days then treated with $50 \mu \mathrm{M}$ TQ for 24 h. MCF7+Dox5+TQ refers to Sen-MCF7 with $100 \mathrm{nM}$ Dox for 5 days then treated with $50 \mu \mathrm{M}$ TQ for 24 h. TQ; thymoquinone.


Figure 6

Bax and Bcl2 protein expressions of proliferative HCT116, Sen-HCT116, and proliferative MCF7, Sen-MCF7 cells by flow cytometry. (A) Bcl2-associated X protein (Bax) protein levels of proliferative and Sen-HCT116. (B) Percentages of Bax protein levels of proliferative and Sen-HCT116. (C) B-cell lymphoma 2 (Bcl2) protein levels of proliferative and Sen-HCT116. (D) Percentages of Bcl2 protein levels of proliferative and Sen-HCT116. (E) Bax protein levels of proliferative and Sen-MCF7. (F) Percentages of Bax protein levels of proliferative and Sen-MCF7. (G) Bcl2 protein levels of proliferative and Sen-MCF7. (H) Percentages of Bcl2 protein levels of proliferative and Sen-MCF7. The data were analyzed with One-way ANOVA (Tukey's Multiple Comparison Test). Error bars represent mean \pm SD. ${ }^{*} \mathrm{P}<0.05$ and ${ }^{\star *} * \mathrm{P}<0.001$ vs. control. $+++\mathrm{P}<0.001$ vs. Dox5. $\mathrm{xP}<0.05, \mathrm{xxP}<$ 0.01 , and $x x x P<0.001$ vs. HCT116+COS or MCF7+COS. Control refers to proliferative-untreated HCT116 or -untreated MCF7. HCT116+COS refers to HCT116 treated with $30 \mu \mathrm{M}$ COS for $24 \mathrm{~h}$. MCF7+COS refers to HCT116 treated with $30 \mu \mathrm{M}$ COS for $24 \mathrm{~h}$. Dox5 refers to Sen-HCT116 or Sen-MCF7 with 100 nM Dox for 5 days. HCT116+Dox5+COS refers to Sen-HCT116 with 100 nM Dox for 5 days then treated with $30 \mu \mathrm{M}$ COS for $24 \mathrm{~h}$. MCF7+Dox5+COS refers to Sen-MCF7 with $100 \mathrm{nM}$ Dox for 5 days then treated with $30 \mu \mathrm{M}$ COS for $24 \mathrm{~h}$. COS; costunolide. 